\title{
Overexpression of S100A14 in human serous ovarian carcinoma
}

\author{
JINGFENG QIAN $^{1}$, FANG DING $^{2}$, AIPING LUO $^{2}$, ZHIHUA LIU $^{2}$ and ZHUMEI CUI ${ }^{1}$ \\ ${ }^{1}$ Department of Obstetrics and Gynecology, Affiliated Hospital of Qingdao University, Qingdao, Shandong 266061; \\ ${ }^{2}$ State Key Laboratory of Molecular Oncology, Cancer Institute and Hospital, \\ Chinese Academy of Medical Sciences and Peking Union Medical College, Beijing 100021, P.R. China
}

Received October 29, 2014; Accepted August 17, 2015

DOI: $10.3892 / 01.2015 .3984$

\begin{abstract}
S100 calcium binding protein A14 (S100A14) is a member of the S100 protein family that plays an important role in the progression of several types of cancer. In the present study, the expression and clinical effect of S100A14 was evaluated in serous ovarian carcinoma (SOC). SOC tissue specimens and a panel of normal ovarian and fallopian tubal tissue specimens were obtained between November 2008 and August 2012 from the Affiliated Hospital of Qingdao University. Immunohistochemistry (IHC) was used to detect the expression of S100A14 in the SOC and normal control tissues. In addition, ELISA was performed to assess S100A14 expression in a subset of serum samples. The association between the expression of S100A14 in SOC and the corresponding clinical and pathological data was analyzed. The IHC results revealed that S100A14 was mainly located in the cytoplasm of the majority of SOC cells, and the expression levels of S100A14 in the tumor tissues were significantly increased compared with the levels identified in normal ovarian specimens $(\mathrm{P}<0.001)$. Consistently, the serum levels of S100A14 in patients with SOC were also increased compared with the levels in healthy individuals $(\mathrm{P}<0.001)$. S100A14 expression was similar in the epithelium of SOC lesions and the fallopian tube, which supported the dualistic model for ovarian serous carcinogenesis. Additional analysis of the expression of S100A14 and corresponding clinical and pathological data revealed the correlation between the elevated expression of S100A14 and resistance to platinum-based chemotherapy. However, the protein level of S100A14 was not associated with the pathological stage, differentiation or metastasis of SOC. Overall, the present results demonstrate that S100A14 is likely to be involved in the resistance of SOC to platinum-based chemotherapy.
\end{abstract}

Correspondence to: Professor Zhumei Cui, Department of Obstetrics and Gynecology, Affiliated Hospital of Qingdao University, 59 Haier Road, Laoshan, Qingdao, Shandong 266061, P.R. China

E-mail: cuizhumei1966@126.com

Key words: S100 calcium binding protein A14, serous ovarian carcinoma, drug resistance

\section{Introduction}

Ovarian cancer is one of the most frequent malignancies of the female reproductive system, with an incidence rate of $\sim 3 \%$ (1), and is the sixth most common type of cancer in women (2). However, the mortality rate associated with ovarian cancer is the highest of the gynecological malignancies. In 2014, the most recent statistics of the American Cancer Society reported that there were $\sim 21,980$ novel cases of ovarian cancer and 14,270 patients that succumbed to ovarian cancer in the USA (3). The latest cancer statistics in China reported the incidence rate of ovarian cancer to be 7.95 cases per 100,000 individuals, and the yearly increase in incidence was higher in urban regions compared with rural regions $(4,5)$. As the ovaries are anatomically located deep within the pelvis, the majority of patients with early-stage ovarian cancer exhibit few specific clinical symptoms, and ovarian cancer continues to lack sensitive and specific biomarkers for early diagnosis in the clinic (6). As a result, the early detection of ovarian cancer is challenging. It has been estimated that $75 \%$ of ovarian cancers are diagnosed at an advanced stage of disease (7). However, tumor resistance to chemotherapy increased the risk of recurrence in patients subsequent to surgery, resulting in a high mortality rate (8). Epithelial ovarian cancer (EOC) is a highly malignant ovarian tumor, the most common type of which is serous ovarian carcinoma (SOC) (9). The dualistic model for ovarian serous carcinogenesis, which states that there are two distinguished types of epithelial carcinoma with different carcinogeneses, was proposed by Singer et al (10) and created a marked impact on the studies investigating SOC, and the clinical treatment of SOC. The origin of ovarian high-grade serous carcinoma (HGSC) has previously been considered to be the fimbria portion of the fallopian tube (11).

The S100 protein family is one of the largest subfamilies of EF-hand calcium-binding proteins, with a molecular weight of $10-12 \mathrm{kDa}$ (12). Currently, the family consists of 25 members (12), of which 16 members are located on chromosome 1q21. Numerous studies have revealed that this chromosomal region is strongly associated with tumorigenesis (13-15). S100 proteins are differentially expressed in a variety of tumors, including breast, esophageal, lung, thyroid, prostate and kidney cancers and oral squamous cell carcinoma (16). In addition, it has been revealed that the S100 proteins play critical roles in tumorigenesis and the development, invasion and metastasis of tumors (17-21). 
Several members of the S100 family are secreted into the serum, and certain members, including S100 calcium binding protein A4 (S100A4), S100A8 and S100A9, were reported as serum biomarkers for the diagnosis and prognosis of malignant tumors $(22,23)$.

The S100A14 protein, which was identified as a novel member of the S100 protein family in 2002, is also located on chromosome 1q21 and exhibits a typical EF-hand structure (24). The expression of S100A14 is significantly different in various normal and tumor tissues (24). Overexpression of S100A14 has been identified in lung, endometrial, breast and cervical cancers, while decreased expression has been observed in lymphoma, and prostate, colorectal and kidney cancers $(24,25)$. S100A14 has been found to be secreted into the culture medium of EC9706 cells, and serum S100A14 has been detected in patients with breast cancer and healthy individuals (26). Currently, the majority of studies investigating S100A14 have focused on the mechanism of tumorigenesis, invasion and metastasis in cancer. S100A14 was expected to become a novel biomarker for metastatic breast cancer $(26,27)$. However, the low expression of S100A14 combined with the overexpression of S100A4 may be a predictive molecular marker for lymph node metastasis in colorectal cancer (28). In addition, S100A14 controls cell invasion through the regulation of matrix metalloproteinase-2 (MMP2), and the regulation of MMP2 by S100A14 is dependent on p53 (29). It has been reported that $\mathrm{SOC}$ demonstrates the highest frequency of p53 mutation in any solid cancer (30), and a previous study confirmed that TP53 was mutated in 303 out of 316 ovarian cancer samples (31). At present, the role and mechanism of S100A14 in the invasion and metastasis of epithelial ovarian cancer remains unclear.

In the present study, immunohistochemistry (IHC) was used to determine the expression of S100A14 in SOC and the normal epithelium of the ovary and fallopian tube. In addition, ELISA was performed to test the level of S100A14 in serum specimens.

\section{Materials and methods}

Patient samples. Formalin-fixed paraffin-embedded blocks and peripheral blood were collected from 125 patients with SOC (mean age, 55 years) at the Department of Gynecology, Affiliated Hospital of Qingdao University (Qingdao, Shandong, China), between November 2008 and August 2012. Of these 125 samples, 103 were HGSC. In total, 52 normal ovarian tissue samples and 10 fallopian tubal tissue samples were obtained from patients that underwent double adnexectomy for the treatment of uterine myoma, and these tissues acted as the normal control tissue samples. The normal control patients were aged between 41 and 69 years, with an average age of 52 years. Furthermore, the pathological diagnoses of all SOC patients were confirmed by two veteran pathologists. No patients had undergone radiotherapy or immunotherapy, and 70 patients had not received pre-operative chemotherapy, but 55 patients had undergone 1 or 2 cycles of platinum-based (cisplatin or carboplatin) and paclitaxel-based pre-operative chemotherapy. In total, 22 sera samples were obtained from patients with SOC prior to surgery, and the remaining sera samples were collected post-operatively. In addition, the control peripheral blood samples were collected from 60 healthy volunteers. The blood samples were frozen at $-80^{\circ} \mathrm{C}$. These tissue samples were characterized according to several clinical and pathological parameters: Patient age; International Federation of Gynecology and Obstetrics (FIGO) stage; differentiation grade; presence of lymph node metastasis; and response to chemotherapy (Table I). The present study was approved by the Ethics Committee of the Affiliated Hospital of Qingdao University. Written informed consent was obtained from all participants.

$I H C$. The experimental formalin-fixed paraffin-embedded tissue wax blocks were put on ice for $30 \mathrm{~min}$ and then continuously sliced into $5-\mu \mathrm{m}$ sections. The tissue sections were incubated at $70^{\circ} \mathrm{C}$ in water and were picked up using 3-aminopropyltriethoxysilane slides (Citoglas, Changzhou, China) and roasted at $75^{\circ} \mathrm{C}$ for $30 \mathrm{~min}$. Prior to staining, the slides were heated in an electric blast oven (DHG-9055A; Shanghai Yiheng Technology Co., Ltd, Shanghai, China) at $60^{\circ} \mathrm{C}$ overnight. The slides were placed in xylene (Beijing Chemical Works, Beijing, China) for deparaffinization and ethyl alcohol (Beijing Chemical Works) for rehydration. The specific steps of deparaffinization and rehydration were as follows: Xylene I and II for $30 \mathrm{~min}$; $100 \%$ ethanol I and II for $10 \mathrm{~min}$; $95 \%$ ethanol for $10 \mathrm{~min}$; $90 \%$ ethanol for $10 \mathrm{~min}$; $80 \%$ ethanol for $10 \mathrm{~min}$; and $70 \%$ ethanol for $10 \mathrm{~min}$. The slides were incubated in $3 \%$ hydrogen peroxide solution (ZSGB-Bio, Beijing, China) for $30 \mathrm{~min}$ at room temperature to eliminate endogenous peroxidase activity. The slides were then heated in citrate buffer (0.01 M; pH 6.0; ZSGB-Bio) for $20 \mathrm{~min}$ at $95^{\circ} \mathrm{C}$ for antigen retrieval, and cooled for $120 \mathrm{~min}$ at room temperature. The slides were blocked with $10 \%$ goat serum (ZSGB-Bio) for $30 \mathrm{~min}$, which was then incubated with rabbit anti-human polyclonal antibody against S100A14 [dilution, 1:100; provided by Dr I. Petersen (Institute of Pathology, University Hospital Charité, Berlin, Germany)] overnight at $4^{\circ} \mathrm{C}$. The slides were washed with phosphate-buffered saline (PBS; ZSGB-Bio) and immersed in Polymer Helper (ZSGB-Bio) for $30 \mathrm{~min}$, and horseradish peroxidase (HRP)-conjugated secondary antibody working solution (ZSGB-Bio) was added to each slide. The slides were incubated for $60 \mathrm{~min}$ at room temperature and 3,3'-diaminobenzidine solution (ZSGB-Bio) was added to the slides prior to observation under the microscope (BH-2 U-PMTVC; Olympus, Tokyo, Japan). As soon as the reaction products were visualized, after $\sim 2 \mathrm{~min}$, the reaction was immediately terminated using PBS. Each slide was stained using hematoxylin (ZSGB-Bio) for $25 \mathrm{sec}$ and dehydrated, and the sections were sealed using neutral resin.

All slides were scanned using the Aperio scanning system (Aperio, San Diego, USA), and Aperio Image Scope software (Aperio) was used for the quantitative analysis of the expression of the S100A14 protein (26). The number of positive cells at x200 magnification was quantified and the staining intensity was assayed. A total of 6-10 fields of the epithelium were randomly selected, counted and the mean was calculated. Finally, the expression score, determined by staining intensity and immunoreactive cell percentage, was output by the aforementioned software (no staining, 0 ; weak positive staining, 1 ; positive staining, 2 ; strong positive staining, 3 ). 
A
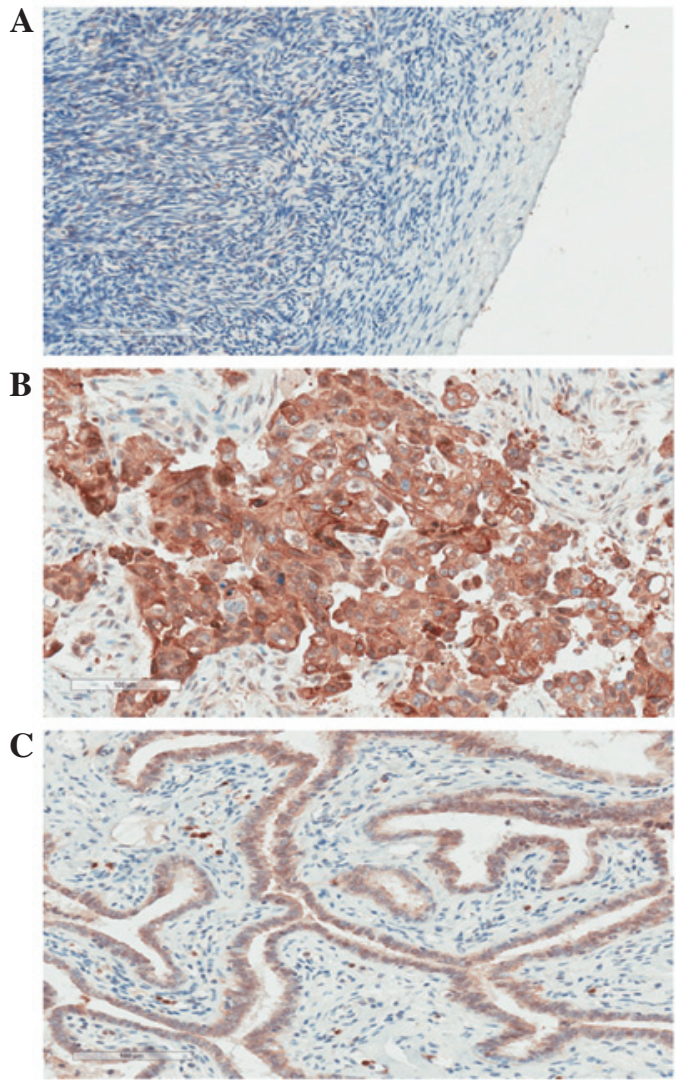

Figure 1. Representative immunohistochemical staining results for $\mathrm{S} 100 \mathrm{cal}-$ cium binding protein A14 in (A) normal ovarian epithelium, (B) serous ovarian carcinoma and (C) normal tubal epithelium tissues (magnification, $\mathrm{x} 200)$.

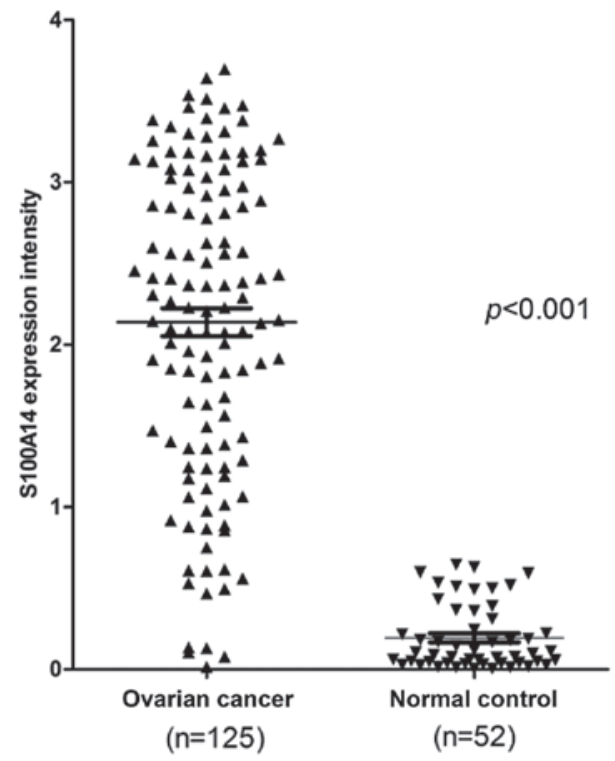

Figure 2. Analysis of the expression of S100A14 in serous ovarian carcinoma and normal ovarian epithelium by immunohistochemistry. The percentage of cells expressing S100A14 and the intensity of the staining was determined using image scope software. S100A14, S100 calcium binding protein A14.

ELISA. A S100A14 ELISA kit (Qisong Biological, Beijing, China) was used to quantitatively detect the levels of soluble S100A14 in the serum of patients and healthy individuals, according to the manufacturer's instructions. The standard curve was plotted according to Qisong Biological. Simultaneously, serum samples from ovarian cancer patients and healthy controls were diluted with dilution buffer (dilution, 1:10; Qisong Biological). All standards and samples were added in duplicate to the microELISA strip plate (Qisong Biological). The samples were incubated for $60 \mathrm{~min}$ at $37^{\circ} \mathrm{C}$ with HRP-conjugate reagent. Chromogens A and B were added to each well, and the reaction was stopped subsequent to incubation for $15 \mathrm{~min}$. The optical density of the wells at $450 \mathrm{~nm}$ was read by a microtiter plate reader (ELx800; BioTek Instruments, Inc., Winooski, VT, USA) within $15 \mathrm{~min}$ of the termination of the reaction.

Statistical analysis. All statistical analyses were performed using SPSS 17.0 software (SPSS, Inc., Chicago, IL, USA). The difference between the expression of S100A14 in patients with SOC and healthy individuals was analyzed using Student's $t$-test and expressed as the mean \pm standard deviation. The association between S100A14 expression and the clinicopathological parameters was also analyzed using Student's $t$-test or one-way analysis of variance followed by Bonferroni's adjustment, accordingly. $\mathrm{P}<0.05$ was considered to indicate a statistically significant difference.

\section{Results}

S100A14 expression is upregulated in SOC tissues compared with normal ovarian epithelial tissues. Firstly, the expression of S100A14 was determined in the normal ovarian and SOC tissues using IHC. The present data revealed that, while there was no expression of S100A14 in normal ovarian tissue slides (Fig. 1A), S100A14 was significantly overexpressed in ovarian cancer tissues. The expression was mainly located in the cytoplasm of cancer cells, and weak expression was observed in the cell membrane and nucleus (Fig. 1B). This finding was further supported by quantitative analysis performed by Aperio Image scope software, which revealed that the score of S100A14 expression in SOC tissues $(1.96 \pm 1.07)$ was markedly increased compared with the score of normal ovarian tissues (0.28 \pm 0.22$)(\mathrm{P}<0.001$; Fig. 2).

S100A14 expression in SOC tissues was in accordance with the expression in normal fallopian tube epithelial tissues. The expression of S100A14 in the normal fallopian tube epithelium was also mainly located in the cytoplasm (Fig. 1C). The score of S100A14 expression in the normal fallopian tubal epithelium was $1.93 \pm 0.84$, which was not significantly different from the scores in the HGSC $(\mathrm{P}=0.8709)$ and SOC $(\mathrm{P}=0.9000)$ tissues (Fig. 3)

Overexpression of S100A14 is associated with resistance to platinum-based chemotherapy. The IHC results were analyzed to investigate the association between S100A14 expression and the clinicopathological parameters of patients, including patient age, FIGO stage, differentiation grade, metastasis and chemotherapeutic efficacy. No significant association was found between S100A14 expression and patient age, tumor size, cancer family history, ascites, pathological stage, tumor differentiation, lymph node metastasis and greater omentum metastasis. 
Table I. Correlation between S100 calcium binding protein A14 expression and clinicopathological features in serous ovarian carcinomas.

\begin{tabular}{|c|c|c|c|}
\hline Clinical and pathological features & Total, n (\%) & Expression score & P-value \\
\hline Age & & & 0.66 \\
\hline$\leq 50$ years & $43(34.4)$ & $1.92 \pm 1.13$ & \\
\hline$>50$ years & $82(65.6)$ & $2.01 \pm 0.99$ & \\
\hline Tumor family history & & & 0.84 \\
\hline Yes & $38(30.4)$ & $2.01 \pm 1.10$ & \\
\hline No & $87(69.6)$ & $1.96 \pm 1.01$ & \\
\hline Tumor size & & & 0.13 \\
\hline$\leq 5 \mathrm{~cm}$ & $58(46.4)$ & $2.13 \pm 1.03$ & \\
\hline$>5 \mathrm{~cm}$ & $67(53.6)$ & $1.85 \pm 1.03$ & \\
\hline Neoadjuvant chemotherapy & & & 0.69 \\
\hline Yes & $55(44.0)$ & $2.02 \pm 0.97$ & \\
\hline No & $70(56.0)$ & $1.94 \pm 1.09$ & \\
\hline Ascites & & & 0.59 \\
\hline Yes & $105(80.4)$ & $1.95 \pm 1.04$ & \\
\hline No & $20(16.0)$ & $2.09 \pm 1.03$ & \\
\hline FIGO stage & & & 0.62 \\
\hline I-II & $22(17.6)$ & $2.09 \pm 1.25$ & \\
\hline III-IV & $103(82.4)$ & $1.95 \pm 0.99$ & \\
\hline Tumor grade & & & 0.76 \\
\hline $1-2$ & $18(14.4)$ & $1.91 \pm 1.16$ & \\
\hline 3 & 107 (85.6) & $1.99 \pm 1.02$ & \\
\hline Lymphatic metastasis & & & 0.39 \\
\hline Yes & $39(31.2)$ & $2.05 \pm 0.98$ & \\
\hline No & $55(44.0)$ & $1.86 \pm 1.05$ & \\
\hline Unknown & $31(24.8)$ & & \\
\hline Omentum metastasis & & & 0.30 \\
\hline Yes & $75(60.0)$ & $2.06 \pm 1.01$ & \\
\hline No & $43(34.4)$ & $1.85 \pm 1.01$ & \\
\hline Unknown & $7(5.6)$ & & \\
\hline Chemotherapy response & & & 0.02 \\
\hline Resistant & $23(18.4)$ & $1.82 \pm 0.96$ & \\
\hline Sensitive & $96(76.8)$ & $1.33 \pm 0.87$ & \\
\hline Uncertain & $6(4.8)$ & & \\
\hline
\end{tabular}

FIGO, International Federation of Gynecology and Obstetrics.

Notably, the expression of S100A14 was significantly different between the platinum-based chemotherapy-resistant group $(1.82 \pm 0.96)$ and the platinum-based chemotherapy-sensitive group $(1.33 \pm 0.87)$ (Table I). The data revealed that overexpression of S100A14 may be associated with platinum-associated chemoresistance.

Serum S100A14 level is significantly increased in patients with SOC compared with the healthy control individuals. To verify the difference between S100A14 expression in the serous ovarian cancer and the normal control, the serum concentration of soluble S100A14 in the two groups was determined by ELISA. The results revealed that the soluble S100A14 levels in patients with serous ovarian adenocarcinoma were markedly increased compared with those of healthy individuals (Fig. 4). This finding indicated that the serum soluble S100A14 concentration may be used as a potential marker for detecting SOC.

\section{Discussion}

The mortality rate of ovarian cancer is the highest of the gynecological cancers, and the overall 5-year survival rate of ovarian cancer is $\sim 45 \%$ (32). Since there are no evident early symptoms of ovarian cancer and there is a lack of sensitive and specific clinical indicators of early diagnosis, $75 \%$ of patients with ovarian cancer are diagnosed at an advanced stage of 


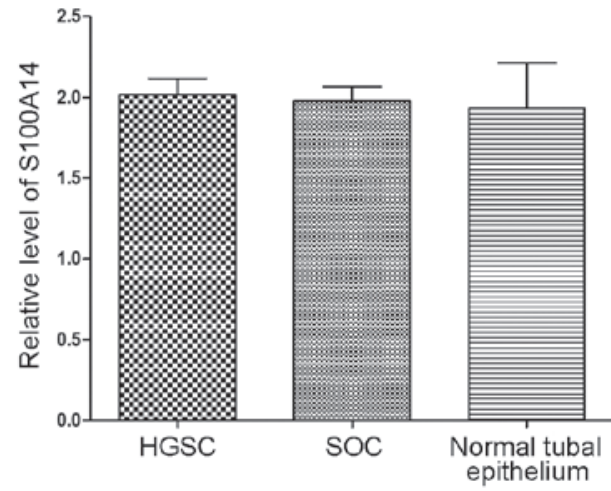

Figure 3. Comparison of the expression of S100A14 in ovarian HGSC, SOC and normal tubal epithelium. HGSC, high-grade serous carcinoma; SOC, serous ovarian carcinoma; S100A14, S100 calcium binding protein A14.

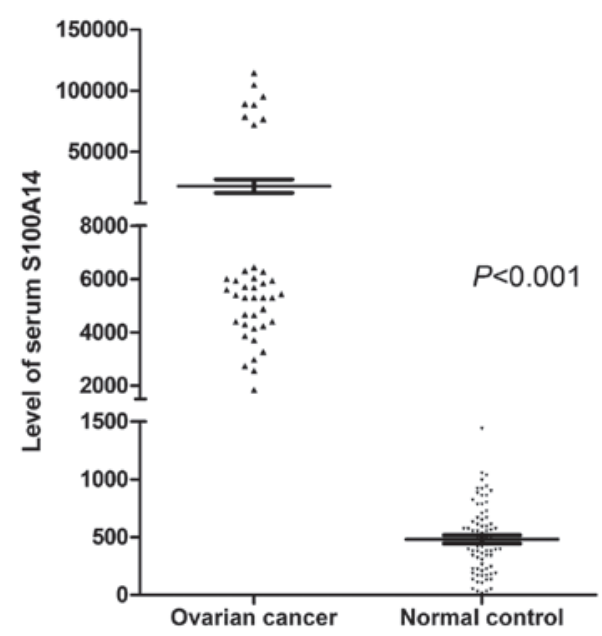

Figure 4. ELISA analysis of S100A14 protein levels in the serum of patients with serous ovarian carcinoma and healthy individuals. S100A14, S100 calcium binding protein A14.

disease $(7,33,34)$. Therefore, the identification and development of biomarkers for ovarian cancer is urgently required.

The expression of the EF-hand calcium-binding protein S100A14 was examined in ovarian cancer and normal ovarian tissue samples in the present study using an immunohistochemistry assay. Firstly, the present results clearly demonstrated that S100A14 is markedly upregulated in ovarian cancers compared with normal ovarian tissues. Next, the correlation between S100A14 and the clinicopathological features of ovarian cancers was analyzed. However, no significant correlation was identified between S100A14 expression and clinicopathological parameters, including tumor size, FIGO grade, presence of lymph node metastasis, family history of cancer and pre-operative chemotherapy.

The expression of S100A14 is considerably different in various tumors, as it is markedly upregulated in several tumors, including breast cancer (26), but expression is downregulated in kidney, colorectal and esophageal cancer (24). In addition, there is a correlation between the upregulation of S100A14 expression and metastasis of breast cancer (27), while low expression is associated with lymph node metastasis in colorectal cancer (28). The present study found that there was no correlation between S100A14 expression and metastasis in ovarian cancer. This may mainly be due to the dominant method of ovarian cancer metastasis being implantation metastasis, not lymphatic metastasis or hematogenous metastasis. By contrast, the present results may be due to the inadequate number of specimens. In future studies, an increased sample size is required to investigate the association between S100A14 expression and the clinicopathological features of ovarian cancer.

The early detection of tumors is critical for improving treatment strategies and patient outcomes. At present, the widely used tumor markers in ovarian cancer, including cancer antigen (CA)125 and CA19-9, demonstrate an unsatisfactory specificity and sensitivity and lack of early diagnostic value. The development of additional molecular markers is strongly required. A simple non-invasive blood test for the early identification of high-risk cancer patients is therefore of particular interest.

S100 proteins play an extracellular function similar to cytokines. The family members of S100A8/S100A9 $(35,36)$, S100A12 (37), S100A13 (38) and S100B $(39,40)$ may be released out of cells actively or passively and bind to the corresponding receptors on the membranes of target cells. In addition, several members of the S100 family have been considered as serum biomarkers in multiple cancers. For example, S100A7 may act as a potential marker in lung cancer (41), serum S100A9 may act as a marker for prostate cancer (42), and S100B is an independent diagnostic and prognostic marker in melanoma (43). Previous studies have also clearly revealed that S100A14 may be secreted by cancer cells and exert extracellular functions (44). Therefore, the serum levels of S100A14 were detected in ovarian cancer patients and healthy individuals in the present study. A significant increase in the S100A14 serum levels was identified in ovarian cancer patients compared with healthy individuals. These results demonstrated that S100A14 may act as a potential marker in ovarian cancer. Future studies may detect changes in the S100A14 serum levels in ovarian cancer patients prior to or following surgery or chemotherapy, to further evaluate the diagnosis and prognosis value of S100A14 in ovarian cancers.

Currently, the main options for the treatment of ovarian cancer are cytoreductive surgery and platinum- and paclitaxel-based chemotherapy. Chemotherapy resistance is a major cause of metastasis and recurrence. EOC accounts for $85-90 \%$ of clinical ovarian malignancies, and SOC is the main type of EOC (45). At present, excision repair cross-complementing rodent repair deficiency, complementation group 1 (ERCC1) is a key topic of studies attempting to predict chemotherapy resistance in ovarian cancer $(46,47)$. The current criteria for evaluating chemoresistance against platinum are based on unchanged tumor size responding to the first-line therapy strategy, tumor progression during chemotherapy, and recurrence within six months post-chemothrapy (48). There is no biomarker to predict the chemotherapeutic response prior to chemotherapy. In addition, the first-line chemotherapy is based on platinum (49). Therefore, platinum-based chemotherapy resistance can only be evaluated subsequent to a period of chemotherapy termination. Previously, the identification of sensitive and specific predictive biomarkers prior to chemotherapy has become a key and challenging topic of studies (48). S100A14 may therefore become a predictive marker for platinum-based chemotherapy response. However, the mechanisms of resistance 
to platinum-based chemotherapy are complex and unclear. The specific mechanism of S100A14 involvement in the resistance of chemotherapy continues to require additional investigation. The S100A14 protein may become a novel molecule for predicting the response to chemotherapy, and a novel target for reversing the resistance to platinum.

In summary, the present study indicates that the expression of S100A14 is significantly upregulated in ovarian serous carcinoma, and the soluble S100A14 levels in the serum of patients with serous ovarian cancer is much higher compared with the level in healthy volunteers. In future studies investigating the biological function of S100A14 in ovarian cancer and verifying the possibility that over-expression of S100A14 may lead to primary drug-resistance to platinum-based chemotherapy, additional experimental testimonies are required.

\section{Acknowledgements}

The authors thank Dr. Iver Petersen and Dr. Youyong Lü for the providing the S100A14 antibodies, and Dr. Yujun Li for the paraffin-embedded formalin-fixed tissues used in this study. The authors also thank Guifeng Wei (Institute of Biophysics, Chinese Academy of Sciences, Beijing, China) for aiding with illustrations.

\section{References}

1. Singh AP, Senapati S, Ponnusamy MP, et al: Clinical potential of mucins in diagnosis, prognosis and therapy of ovarian cancer. Lancet Oncol 9: 1076-1085, 2008.

2. Lin KT, Yeh YM, Chuang CM, Yang SY, Chang JW, Sun SP, Wang YS, Chao KC and Wang LH: Glucocorticoids mediate induction of microRNA-708 to suppress ovarian cancer metastasis through targeting Rap1B. Nat Commun 6: 5917, 2015.

3. Siegel R, Ma J, Zou Z and Jemal A: Cancer statistics, 2014. CA Cancer J Clin 64: 9-29, 2014.

4. Chen W, Zheng R, Zhang S, Zhao P, Li G, Wu L and He J: The incidences and mortalities of major cancers in China, 2009. Chin J Cancer 32: 106-112, 2013.

5. Chen W, Zheng R, Zhang S, Zhao P, Li G, Wu L and He J: Report of incidence and mortality in China cancer registries, 2009. Chin J Cancer Res 25: 10-21, 2013.

6. Gubbels JA, Claussen N, Kapur AK, Connor JP and Patankar MS: The detection, treatment, and biology of epithelial ovarian cancer. J Ovarian Res 3: 8, 2010.

7. Schummer M, Ng WV, Bumgarner RE, Nelson PS, Schummer B, Bednarski DW, Hassell L, Baldwin RL, Karlan BY and Hood L: Comparative hybridization of an array of 21,500 ovarian cDNAs for the discovery of genes overexpressed in ovarian carcinomas. Gene 238: 375-385, 1999.

8. Eisenhauer EL, Abu-Rustum NR, Sonoda Y, Aghajanian C, Barakat RR and Chi DS: The effect of maximal surgical cytoreduction on sensitivity to platinum-taxane chemotherapy and subsequent survival in patients with advanced ovarian cancer. Gynecol Oncol 108: 276-281, 2008.

9. Barger CJ, Zhang W, Hillman J, Stablewski AB, Higgins MJ, Vanderhyden BC, Odunsi K and Karpf AR: Genetic determinants of FOXM1 overexpression in epithelial ovarian cancer and functional contribution to cell cycle progression. Oncotarget 6 : 27613-27627, 2015.

10. Singer G, Kurman RJ, Chang HW, Cho SK and Shih IeM: Diverse tumorigenic pathways in ovarian serous carcinoma. Am J Pathol 160: 1223-1228, 2002.

11. Kuhn E, Kurman RJ, Vang R, Sehdev AS, Han G, Soslow R, Wang TL and Shih IeM: TP53 mutations in serous tubal intraepithelial carcinoma and concurrent pelvic high-grade serous carcinoma-evidence supporting the clonal relationship of the two lesions. J Pathol 226: 421-426, 2012.

12. Heizmann CW, Fritz G and Schäfer BW: S100 proteins: Structure, functions and pathology. Front Biosci 7: d1356-d1368, 2002.
13. Schäfer BW, Wicki R, Engelkamp D, Mattei MG and Heizmann CW: Isolation of a YAC clone covering a cluster of nine S100 genes on human chromosome 1q21: Rationale for a new nomenclature of the $\mathrm{S} 100$ calcium-binding protein family. Genomics 25: 638-643, 1995 .

14. Weterman MA, Wilbrink M, Dijkhuizen T, van den Berg E and Geurts van Kessel A: Fine mapping of the 1q21 breakpoint of the papillary renal cell carcinoma-associated $(\mathrm{X} ; 1)$ translocation. Hum Genet 98: 16-21, 1996.

15. Gendler SJ, Cohen EP, Craston A, Duhig T, Johnstone G and Barnes D: The locus of the polymorphic epithelial mucin (PEM) tumour antigen on chromosome 1q21 shows a high frequency of alteration in primary human breast tumours. Int J Cancer 45: 431-435, 1990.

16. Bresnick AR, Weber DJ and Zimmer DB: S100 proteins in cancer. Nat Rev Cancer 15: 96-109, 2015.

17. Huttunen HJ, Kuja-Panula J, Sorci G, Agneletti AL, Donato R and Rauvala $\mathrm{H}$ : Coregulation of neurite outgrowth and cell survival by amphoterin and S100 proteins through receptor for advanced glycation end products (RAGE) activation. J Biol Chem 275: 40096-40105, 2000.

18. Filipek A, Jastrzebska B, Nowotny M and Kuznicki J: CacyBP/SIP, a calcyclin and Siah-1-interacting protein, binds EF-hand proteins of the S100 family. J Biol Chem 277: 28848-28852, 2002.

19. Arumugam T, Simeone DM, Schmidt AM and Logsdon CD: S100P stimulates cell proliferation and survival via receptor for activated glycation end products (RAGE). J Biol Chem 279: 5059-5065, 2004.

20. Fernandez-Fernandez MR, Veprintsev DB and Fersht AR: Proteins of the S100 family regulate the oligomerization of p53 tumor suppressor. Proc Natl Acad Sci USA 102: 4735-4740, 2005.

21. Zhang HY, Zheng XZ, Wang XH, Xuan XY, Wang F and Li SS: S100A4 mediated cell invasion and metastasis of esophageal squamous cell carcinoma via the regulation of MMP-2 and E-cadherin activity. Mol Biol Rep 39: 199-208, 2012.

22. Donato R: S100: A multigenic family of calcium-modulated proteins of the EF-hand type with intracellular and extracellular functional roles. Int J Biochem Cell Biol 33: 637-668, 2001.

23. Zimmer DB, Cornwall EH, Landar A and Song W: The S100 protein family: History, function and expression. Brain Res Bull 37: 417-429, 1995.

24. Pietas A, Schlüns K, Marenholz I, Schafer BW, Heizmann CW and Petersen I: Molecular cloning and characterization of the human S100A14 gene encoding a novel member of the S100 family. Genomics 79: 513-522, 2002.

25. Chen H, Yu D, Luo A, Tan W, Zhang C, Zhao D, Yang M, Liu J, Lin D and Liu Z: Functional role of S100A14 genetic variants and their association with esophageal squamous cell carcinoma. Cancer Res 69: 3451-3457, 2009.

26. Xu C, Chen H, Wang X, Gao J, Che Y, Li Y, Ding F, Luo A, Zhang S and Liu Z: S100A14, a member of EF-hand calcium-binding proteins, is overexpressed in breast cancer and acts as a modulator of HER2 signaling. J Biol Chem 289: 827-837, 2014.

27. Leth-Larsen R, Terp MG, Christensen AG, Elias D, Kühlwein T, Jensen ON, Petersen OW and Ditzel HJ: Functional heterogeneity within the CD44 high human breast cancer stem cell-like compartment reveals a gene signature predictive of distant metastasis. Mol Med 18: 1109-1121, 2012.

28. Wang HY, Zhang JY, Cui JT, Tan XH, Li WM, Gu J and Lu YY: Expression status of S100A14 and S100A4 correlates with metastatic potential and clinical outcome in colorectal cancer after surgery. Oncol Rep 23: 45-52, 2010.

29. Chen H, Yuan Y, Zhang C, Luo A, Ding F, Ma J, Yang S, Tian Y, Tong T, Zhan Q and Liu Z: Involvement of S100A14 protein in cell invasion by affecting expression and function of matrix metalloproteinase (MMP)-2 via p53-dependent transcriptional regulation. J Biol Chem 287: 17109-17119, 2012.

30. Ahmed AA, Etemadmoghadam D, Temple J, Lynch AG, Riad M, Sharma R, Stewart C, Fereday S, Caldas C, Defazio A, et al: Driver mutations in TP53 are ubiquitous in high grade serous carcinoma of the ovary. J Pathol 221: 49-56, 2010.

31. Cancer Genome Atlas Research Network: Integrated genomic analyses of ovarian carcinoma. Nature 474: 609-615, 2011.

32. Siegel R, Naishadham D and Jemal A: Cancer statistics, 2012. CA Cancer J Clin 62: 10-29, 2012.

33. Farley J, Ozbun LL and Birrer MJ: Genomic analysis of epithelial ovarian cancer. Cell Res 18: 538-548, 2008.

34. Karst AM and Drapkin R: Ovarian cancer pathogenesis: A model in evolution. J Oncol 2010: 932371, 2010. 
35. Katano M, Okamoto K, Suematsu N, Kurokawa MS, Nakamura H, Masuko K, Yudoh $\mathrm{K}$ and Kato T: Increased expression of S100 calcium binding protein A8 in GM-CSF-stimulated neutrophils leads to the increased expressions of IL-8 and IL-16. Clin Exp Rheumatol 29: 768-775, 2011.

36. Grebhardt S, Veltkamp C, Ströbel P and Mayer D: Hypoxia and HIF-1 increase S100A8 and S100A9 expression in prostate cancer. Int J Cancer 131: 2785-2794, 2012.

37. Foell D, Seeliger S, Vogl T, Koch HG, Maschek H, Harms E, Sorg C and Roth J: Expression of S100A12 (EN-RAGE) in cystic fibrosis. Thorax 58: 613-617, 2003.

38. Matsunaga $\mathrm{H}$ and Ueda $\mathrm{H}$ : Evidence for serum-deprivation-induced co-release of FGF-1 and S100A13 from astrocytes. Neurochem Int 49: 294-303, 2006.

39. Leite MC, Galland F, de Souza DF, Guerra MC, Bobermin L, Biasibetti R, Gottfried C and Gonçalves CA: Gap junction inhibitors modulate S100B secretion in astrocyte cultures and acute hippocampal slices. J Neurosci Res 87: 2439-2446, 2009.

40. Li R, Xia W, Zhang Z and Wu K: S100B protein, brain-derived neurotrophic factor and glial cell line-derived neurotrophic factor in human milk. PLoS One 6: e21663, 2011.

41. Zhang H, Zhao Q, Chen Y, Wang Y, Gao S, Mao Y, Li M, Peng A, $\mathrm{He} D$ and Xiao X: Selective expression of S100A7 in lung squamous cell carcinomas and large cell carcinomas but not in adenocarcinomas and small cell carcinomas. Thorax 63: 352-359, 2008.

42. Hermani A, Hess J, De Servi B, Medunjanin S, Grobholz R, Trojan L, Angel P and Mayer D: Calcium-binding proteins S100A8 and S100A9 as novel diagnostic markers in human prostate cancer. Clin Cancer Res 11: 5146-5152, 2005.

43. Martenson ED, Hansson LO, Nilsson B, von Schoultz E, Månsson Brahme E, Ringborg U and Hansson J: Serum S-100b protein as a prognostic marker in malignant cutaneous melanoma. J Clin Oncol 19: 824-831, 2001.
44. Jin Q, Chen H, Luo A, Ding F and Liu Z: S100A14 stimulates cell proliferation and induces cell apoptosis at different concentrations via receptor for advanced glycation end products (RAGE). PLoS One 6: e19375, 2011

45. Kaku T, Ogawa S, Kawano Y, Ohishi Y, Kobayashi H, Hirakawa T and Nakano H: Histological classification of ovarian cancer. Med Electron Microsc 36: 9-17, 2003.

46. Smith S, Su D, Rigault de la Longrais IA, Schwartz P, Puopolo M, Rutherford TJ, Mor G, Yu H and Katsaros D: ERCC1 genotype and phenotype in epithelial ovarian cancer identify patients likely to benefit from paclitaxel treatment in addition to platinum-based therapy. J Clin Oncol 25: 5172-5179, 2007.

47. Krivak TC, Darcy KM, Tian C, Armstrong D, Baysal BE, Gallion H, Ambrosone CB and DeLoia JA; Gynecologic Oncology Group Phase III Trial: Relationship between ERCC1 polymorphisms, disease progression and survival in the gynecologic oncology group phase III trial of intraperitoneal versus intravenous cisplatin and paclitaxel for stage III epithelial ovarian cancer. J Clin Oncol 26: 3598-3606, 2008.

48. Colombo PE, Fabbro M, Theillet C, Bibeau F, Rouanet P and Ray-Coquard I: Sensitivity and resistance to treatment in the primary management of epithelial ovarian cancer. Crit Rev Oncol Hematol 89: 207-216, 2014.

49. Angioli R, Capriglione S, Aloisi A, Guzzo F, Luvero D, Miranda A, Damiani P, Montera R, Terranova C and Plotti F: Can HE4 predict platinum response during first-line chemotherapy in ovarian cancer? Tumour Biol 35: 7009-7015, 2014. 